\title{
Áreas de Influência: Uma metodologia de leitura para compreensão sobre as áreas contaminadas que incidem na população e na área territorial dos municípios
}

Hinterlands: A reading methodology for understanding of the contaminated areas that focus on population and land area of the municipalities.

Zonas de influencia: una metodología de lectura para la comprensión de las áreas contaminadas que se centran en la población y la extensión territorial de los municipios.

Ricardo Alexandre da Silva Doutorando, PósUrb - PUCCampinas, Brasil. ricardosilvaarq@gmail.com

Laura Machado de Mello Bueno Professora Doutora, PósUrb - PUCCampinas, Brasil. laurabueno500@gmail.com 


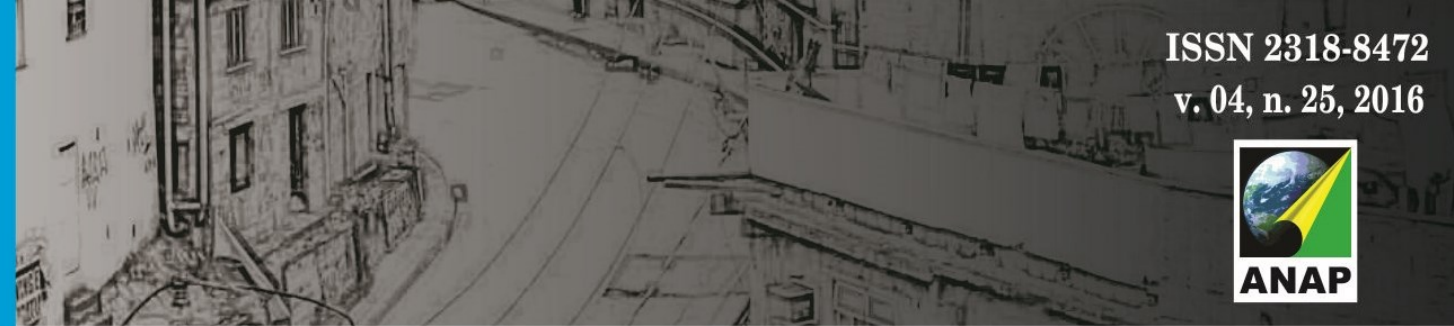

Gerenciamento de Cidades

adotam uma postura de resiliência as adversidades à ocupação do solo, não contemplando e não produz os meios de acesso para a solução das necessidades e nem para uma vida urbana integrada. Esses mesmos grupos acabam submetidos aos mais variados riscos ambientais, ao não dispor de condições de se fazer ouvir no espaço público, pois a sua condição de fragilidade e desamparo está relacionada a possíveis mudanças de condições ocorridas em seu entorno. A situação é ampliada pela ausência de estruturas e políticas públicas, gerando insegurança, desmotivação e paralisia, já que não existe a oportunidade de colocar em questão os efeitos da desigual distribuição da poluição e da proteção ambiental. Deste modo, a regressão de direitos dessas comunidades locais, configura esse grupo como uma sociedade de risco (SANCHEZ, 2001; VIEGAS, 2006 e RAMIRES, 2008).

Em relação aos grupos sociais, os que são vulnerabilizados por processos que ferem a autodefesa contra agravos são as populações com modo de vida indissociável do meio em que vivem, pois precisam do livre acesso a um a ambiente saudável para sua subsistência e reprodução; e também, as populações urbanas deslocadas de sua área de origem por projetos de "desenvolvimento" dos quais foram excluídas. Este último está posicionado nas populações rurais e nos meios urbanos, os imigrantes e ocupantes dos piores solos, que estão mais sujeitos a sofrer com os danos causados pelas áreas contaminadas. (FASE/ETTERN IPPUR/UFRJ, 2011).

O termo vulnerabilidade ${ }^{1}$ é claro ao vincular a magnitude do impacto previsível de uma álea ${ }^{2}$, evento extremo ou com os alvos com potencial de risco. Trata-se de uma sujeição maior aos riscos, uma menor capacidade de resposta durante e após a ocorrência do evento. Pode ser humana, socioeconômica e ambiental, mas é mais amplamente utilizada para se referir a pessoas, grupos sociais ou a ação do Estado. A palavra risco pode ser definida em diversos sentidos e contextos. O risco ambiental está diretamente ligado ao meio ambiente natural, e as relações de interação sistêmicas com os meios envoltos a ele, e nas cidades procura estabelecer e compreender como as atividades antrópicas provocam alterações no meio ambiente e afetam a saúde e o bem estar da população que vive ao seu redor e também em todo o espaço urbano. Os riscos existentes podem ser encontrados cotidianamente em diferentes lugares, em diferentes contextos com outros riscos e com outras características, podendo ser conhecidos, ou seja, são passiveis de mensuração e controle, mitigação ou simplesmente desconhecidos. Um aspecto muito importante são as formas de como os riscos estão distribuídos no território, e as possíveis relações existentes entre diferentes formas de risco o que pode caracterizar é uma espacialização distribuída (MARQUES \& TORRES, 2003). E

\footnotetext{
1 Existem diversas definições acerca do termo, porém o que parece mais adequado é o que trata de "vulnerabilidade socioeconômica" que segundo Vignoli, (2000 Apud Cunha, 2006), correlaciona também vulnerabilidade demográfica. Em outros termos, considera-se características demográficas de um domicilio (estrutura etária, sexo do chefe de família, razões de dependência) em determinados momentos sócio econômicos, ensejariam riscos próprios ou contribuiriam, ou não, para sua vulnerabilidade social, ou seja, comprometeriam sua capacidade aos riscos sociais.

2 Álea é um acontecimento possível, seja ele de origem natural, social, tecnológica ou econômica (MENDES, 2011).
} 


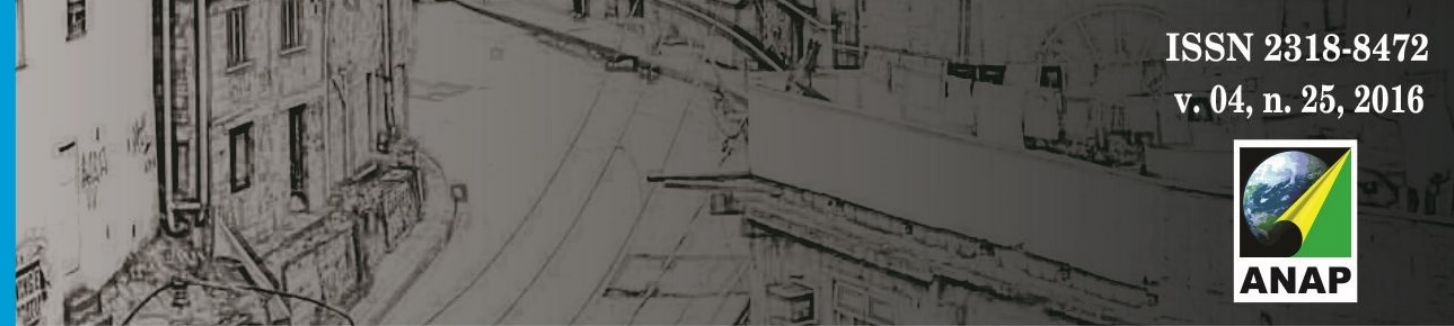

Revista Nacional de Gerenciamento de Cidades

como ação direta de ações antrópicas, temos a amplificação dos impactos gerados no espaço territorial, que envolvem desde espaços urbanos de grande qualidade sócio espaciais, e o oposto, que são os espaços desprovidos de quaisquer elementos qualificativos e que são direcionados para atividades menos nobres, como a exploração de matérias primas para a construção, o descarte de resíduos e contaminantes resultantes da produção industrial. A expressão Zonas de Sacrifício é utilizada pelos movimentos de justiça ambiental para designar estas localidades onde existe uma superposição de empreendimentos e instalações responsáveis por danos e riscos ambientais (ACSELRAD, 2004; 2006 e VIÉGAS, 2006). As populações de baixa renda, situadas nos espaços menos qualificados, são as principais vítimas, exatamente porque os impactos indesejáveis provenientes dos grandes investimentos resultam da apropriação dos recursos existentes no território que, ao concentrarem a renda e o poder, afetam a saúde dos trabalhadores e a integridade dos ecossistemas. Além dos agentes do capital, a municipalidade também tem contribuído especialmente ao introduzir leis de uso e ocupação do solo que negam o seu papel como agente ordenador das ações executadas no espaço municipal, e buscam fortalecer a concretização do "direito a cidades sustentáveis", sendo entendido como o direito à terra urbana, à moradia, ao saneamento ambiental, à infraestrutura urbana, ao transporte e aos serviços públicos, ao trabalho e ao lazer (CARVALHO \& ROSSBACH, 2013).

O quadro traçado configura a realidade de muitas localidades em muitas cidades do Brasil, configurando um quadro de desigualdades que é a resultante dos processos intensos e acelerados, decorrentes da industrialização maciça do território, e também não podemos deixar de considerar, que foi um processo derivado da aplicação de leis urbanas, e que resultaram na realidade discrepante para maioria da população da cidade, em níveis inaceitáveis de vulnerabilidades sociais, e que refletem diretamente em todos os grupos sociais que abarcam a cidade como um todo. Com isso tem-se como cenário um tipo de urbanização que ao serem condicionadas pela industrialização, revelou uma face perversa, ao introduzir os riscos de acidentes ambientais incidentes sobre estas populações, relacionando as áreas ociosas no espaço urbano e rural com a presença de possíveis contaminações do solo, ar e meios hídricos (LOCATELLI, 2006; MINDRIZ, 2006 e FARIA, 2012).

\section{Objetivos}

O artigo em questão, procura discutir a questão da situação de risco a partir do levantamento das áreas contaminadas e sua influencia no espaço municipal. Propõe estabelecer uma nova leitura, em que as áreas contaminadas, devem ser consideradas de modo amplificado, quanto localização e a influência de possíveis danos no território municipal. Uma apresentação do problema e uma análise crítica serão feitas, afim de identificar os principais prejuízos, e cujo os resultados, irão propor a aplicação de novas diretrizes para áreas que criem situações de risco. 


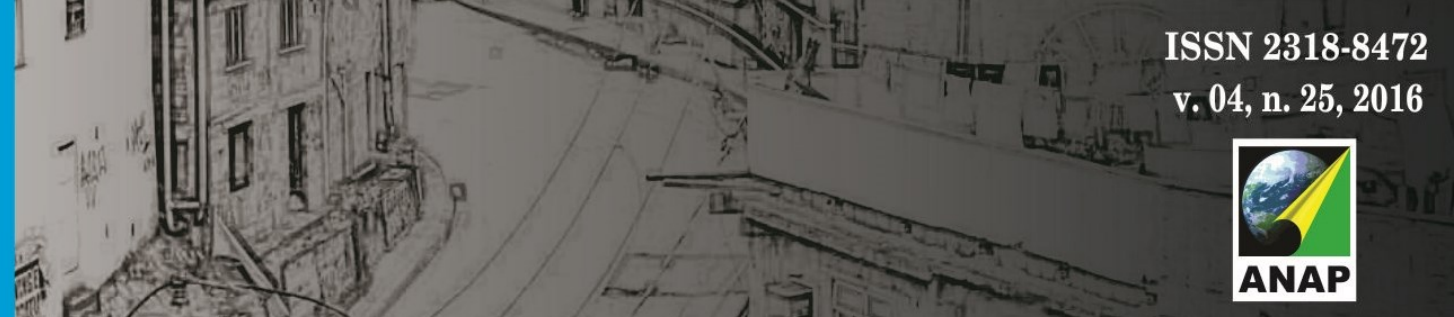

Revista Nacional de Gerenciamento de Cidades

\section{1 - 0 tratamento das áreas contaminadas no Estado de São Paulo}

A questão da contaminação do solo e das águas subterrâneas já é objeto de grande preocupação e definição de políticas públicas nas últimas cinco décadas (principalmente a partir dos anos 1960) em países da Europa e América do Norte (TROVÃO, 2006). No Brasil as preocupações e ações são mais recentes. Esse problema tem adquirido importantes proporções em grandes centros urbanos, principalmente nas áreas metropolitanas e distritos industriais antigos. Destacam-se a região do $A B C$ e a região sul de São Paulo, na RMSP, o Porto de Santos, Cubatão, no ESP, além do Rio de Janeiro, o Porto do Rio de Janeiro e Baixada Fluminense (BRANCO, 1984; GUIBERLET, 1996; ACSELRAD, 2006). Desde 2002 o Governo do Estado de São Paulo (ESP), por meio da Companhia de Tecnologia de Saneamento Ambiental (CETESB) divulga listas de áreas comprovadamente contaminadas por produtos químicos por empresas poluentes. O cadastro, pioneiro no Brasil (INEA, 2016), é decorrência de acidentes recentes, quando se percebeu que as causas decorriam de atividades impactantes antigas, anteriores à legislação ambiental brasileira de 1981. Para a execução deste levantamento, a CETESB teve como suporte técnico e financeiro a participação da GIZ - Deutsche Gesellschaft für Internationale Zusammenarbeit (entidade alemã de cooperação internacional, 2016), após detectar a ocorrência de explosões e contaminação de trabalhadores em empreendimentos imobiliários em áreas industriais desativadas no Estado de São Paulo. Desde então a CETESB tem procedimentos constantes de identificação de casos, avaliação de risco e contaminação, projetos de remediação e recuperação (SILVA, 2013: 83). Em números absolutos, as áreas comprovadamente contaminadas cadastradas no ESP, passaram de 257, em 2002, para 4771 em 2013. A expansão da urbanização em todo o Estado alcançou em muitos casos, áreas antes rurais utilizadas para despejo de contaminantes, fazendo com que o poder público se debruçasse sobre o problema. $\mathrm{O}$ crescimento anual se deve à percepção, tanto dos técnicos, quanto da sociedade sobre os problemas ambientais e maior mobilização e denúncias. Em decorrência de estudos internos e denúncias, a CETESB visita e avalia os locais com atividades econômicas ativas e ou inativas, registrando o novo caso no Cadastro. 
Tabela 1: Áreas contaminadas no Estado de São Paulo

\begin{tabular}{lcccccc}
\hline Região & Comercial & Industrial & Resíduos & $\begin{array}{c}\text { Posto de } \\
\text { Combustíveis }\end{array}$ & $\begin{array}{c}\text { Acidentes/Desconhecida/ } \\
\text { Agricultura }\end{array}$ & Total \\
São Paulo & 76 & 248 & 38 & 1.294 & 09 & 1.665 \\
RMSP - outros & 48 & 199 & 23 & 535 & 11 & 816 \\
Interior & 75 & 228 & 45 & 1.314 & 15 & 1.677 \\
Litoral & 29 & 42 & 28 & 247 & 02 & 348 \\
Vale do Paraíba & 04 & 51 & 02 & 207 & 01 & 265 \\
\hline Total & 232 & 768 & 136 & 3.597 & 38 \\
\hline \multicolumn{7}{r}{} \\
\hline
\end{tabular}

Fonte: CETESB, 2013

A distribuição espacial (Tabela 1) reflete a própria história da industrialização paulista - $52 \%$ dos locais estão na Região Metropolitana de São Paulo (RMSP), sendo 35 \% na capital. 0 interior do Estado, somando-se litoral e Vale do Paraíba, soma 2290 áreas. A maioria é composta por Postos de Combustíveis (CETESB, 2013), localizados geralmente no espaço intraurbano. É frágil o controle do comportamento deste setor sobre os modos de transporte $\mathrm{e}$ acondicionamento de combustíveis, bem como manutenção periódica dos tanques (CETESB, 2013). A Legislação federal ${ }^{3}$ que regula a implantação e licenças periódicas de postos no meio urbano foi criada somente a partir de 2000, e no Estado de São Paulo há um decreto de 1994. Além de postos de gasolina, as atividades que mais contaminam as áreas urbanas são as indústrias - 768 (16\%, metade dos casos na RMSP), empresas de comércio/serviços - 232 (5\%), depósitos de resíduos - 136 (3\%), além dos acidentes. Nesta questão as deficiências são gritantes, como a falta de um manejo seguro, aliado a falhas e vazamentos no transporte viário, por dutos e ou armazenamento, encarados apenas como erros casuais, sem avaliação prévia das consequências ao meio urbano local e ao meio ambiente.

\section{Aspectos metodológicos}

Está dentro de uma pesquisa mais ampla, onde muitas destas áreas contaminadas estão vinculadas as atividades industriais em rede regional em várias escalas. Numa primeira etapa, é realizado um levantamento de casos presentes no território metropolitano, segundo o ramo de atividade e os tipos de atividades potencialmente contaminantes (posto de combustível, indústria, comercio e serviços, resíduos e agricultura) no espaço urbano e rural. Numa segunda etapa, munido do total de áreas contaminadas feito em cada município, é realizado uma equação matemática, para determinar a quantidade de áreas contaminadas para cada 10.000 mil habitantes em comparação a população total do município. Numa terceira etapa, é feita

\footnotetext{
${ }^{3}$ As resoluções CONAMA 273/2000, 319/2002 e 362/2005, as portarias da ANP de 1999 e 2000, assim como normas do INMETRO.
} 
uma nova operação matemática, cruzando-se a área total do território municipal com o número total de áreas contaminadas levantadas em cada município.

\section{Resultados}

\section{1. Áreas contaminadas na Região Metropolitana de Campinas e seus impactos}

A RMC ${ }^{4}$ é composta por 20 municípios e tem uma população de 3.094,181 habitantes, ou 6,8\% do total estadual (93,20\%). Apresenta cinco municípios com população superior a 200.000 habitantes: Campinas (1.164,098 hab.), Sumaré (265.955 hab.), Indaiatuba (231.033 hab.), Americana (229.322 hab.) e Hortolândia (215.819 hab.). Três municípios (Santa Barbara d'Oeste, Valinhos e Itatiba) possuem população entre 100.000 e 200.000 habitantes, outros quatro entre 50.000 e 100.000 habitantes, e oito entre 10.000 e 50.000 habitantes. O PIB per capita da RMC (R\$37.183,64) é superior ao estadual ( $R \$ 32.454,91)$ e o nacional (R\$ 31.506,83). Dentre os municípios da RMC, Paulínia possui o maior PIB per capita regional (R\$ $99.172,47)$, seguido de Vinhedo ( $R \$ 71.364,01)$, Jaguariúna ( $R \$ 48.351,78$ ) e Holambra ( $R \$$ 43.810,19). O município de Campinas ( $\mathrm{R} \$ 33.939,56$ ) possui um PIB per capita um pouco abaixo da média da RMC e, Morungaba (R\$ 15.996,84) e Artur Nogueira (R\$ 12.278,51), possuem os menores PIBs per capita numa região que apresenta importantes disparidades espaciais, sociais e de renda em suas periferias. (BAENINGER, 2001 e IBGE, 2013). A Tabela 3 apresenta o número das áreas contaminadas nos municípios da RMC desde 2002, distribuídas pelos municípios.

A Região Metropolitana de Campinas foi criada pela lei complementar estadual 870/2000. http://www.seade.gov.br/. Acessado em 30 julho de 2016. 
Tabela 2 - Áreas contaminadas na Região Metropolitana de Campinas - RMC

\begin{tabular}{|c|c|c|c|c|c|c|c|c|c|c|c|c|c|}
\hline Títulos & & & & Númer & de ár & as Cont & minada & -2002 & a 2013 & & & & \\
\hline $\begin{array}{l}\text { Municípios } \\
\text { da RMC }\end{array}$ & 2002 & 2003 & 2004 & 2005 & 2006 & 2007 & 2008 & 2009 & 2010 & 2011 & 2012 & 2013 & Tota \\
\hline Americana & - & 01 & 05 & - & 01 & 01 & - & - & 03 & 09 & 03 & - & 23 \\
\hline $\begin{array}{l}\text { Artur } \\
\text { Nogueira }\end{array}$ & - & 01 & - & 01 & - & - & - & - & 01 & - & 02 & 01 & 06 \\
\hline Campinas & 07 & 03 & 23 & 12 & 01 & 40 & 06 & 08 & 11 & 09 & 10 & 03 & 133 \\
\hline Cosmópolis & 01 & - & 01 & 01 & - & 04 & - & - & - & 02 & - & - & 09 \\
\hline $\begin{array}{l}\text { Engenheiro } \\
\text { Coelho }\end{array}$ & - & 01 & - & - & - & - & - & - & - & - & - & - & 01 \\
\hline Holambra & - & - & - & - & - & 01 & - & 01 & - & - & - & 01 & 03 \\
\hline Hortolândia & - & - & 02 & - & - & 02 & - & - & 02 & 05 & 01 & 01 & 13 \\
\hline Indaiatuba & 01 & - & 01 & - & 01 & 01 & - & - & 09 & 02 & 01 & - & 16 \\
\hline Itatiba & 01 & - & 08 & - & - & - & 02 & 04 & 05 & 01 & 02 & 01 & 24 \\
\hline Jaguariúna & - & - & - & 02 & - & - & - & 03 & 01 & 02 & 01 & - & 09 \\
\hline Monte Mor & 01 & - & - & - & - & - & - & 01 & - & - & - & - & 02 \\
\hline Morungaba & - & - & - & - & - & - & - & - & - & - & - & - & - \\
\hline $\begin{array}{l}\text { Nova } \\
\text { Odessa }\end{array}$ & - & - & - & - & 01 & - & - & 01 & - & - & 01 & - & 03 \\
\hline Paulínia & 06 & 07 & 12 & 02 & - & 04 & 05 & 09 & 03 & 13 & 04 & - & 65 \\
\hline Pedreira & - & - & 03 & 01 & 02 & 02 & 01 & - & - & 01 & - & 01 & 11 \\
\hline $\begin{array}{l}\text { Santa } \\
\text { Barbara } \\
\text { d'Oeste }\end{array}$ & - & 01 & - & 01 & 01 & 01 & 01 & 01 & 021 & 07 & - & - & 14 \\
\hline $\begin{array}{l}\text { Santo } \\
\text { Antônio de } \\
\text { posse }\end{array}$ & 02 & - & 01 & - & - & - & - & - & - & - & - & - & 03 \\
\hline Sumaré & 03 & 01 & 01 & 02 & - & 03 & 01 & - & - & 06 & 04 & 03 & 24 \\
\hline Valinhos & 01 & 01 & 03 & 02 & - & 01 & 01 & 01 & 03 & - & 01 & 02 & 16 \\
\hline Vinhedo & - & - & - & 02 & - & 01 & 01 & - & 04 & - & - & 01 & 09 \\
\hline Total & 23 & 16 & 60 & 26 & 07 & 61 & 18 & 29 & 43 & 48 & 30 & 14 & 384 \\
\hline Anual \% & - & 69,56 & 375 & 43,3 & 26,9 & 871,4 & 29,5 & 161,1 & 148,2 & 111,6 & 62,5 & 46,6 & - \\
\hline
\end{tabular}

Fonte: elaboração do autor sobre dados da CETESB, 2013.

Em comum, tiveram como processo de industrialização as intensas transformações geradas pelo processo de interiorização paulista a partir de Campinas, entre as décadas de $1950 \mathrm{e}$ 1970. Quanto ao interno, correspondente ao aglomerado urbano, que estabeleceu uma base industrial expressiva, dinâmica e compartilhada, e áreas conflitantes entre moradia, indústria e passivos ambientais oriundos de antigas fontes de contaminação ativas ou desativadas. $\mathrm{Na}$ RMC atualmente existem 384 áreas contaminadas cadastradas. Na linha final calculou-se o crescimento relativo ano a ano, da identificação das áreas. Destaca-se que de 2003 para 2004, foram identificadas na RMC 60 áreas, um acréscimo de 375\%. Também se destaca 2007 com identificação de 61 novas áreas, $871,4 \%$ de crescimento. Em relação a 2004, as áreas contaminadas tiveram o acréscimo de 44 áreas entre 2003/2004. Já ao considerar o ano de 2007, mais 54 áreas foram detectadas entre 2006/2007. Diferentemente do município de São 
Paulo e da RMSP (Tabela 2), onde os postos de gasolina são a grande maioria das áreas contaminadas, na RMC o número de postos e de indústrias com problemas é semelhante. A Tabela 3 abaixo apresenta os ramos de atividade que causaram a contaminação nos municípios da RMC.

Tabela 3 - Relação de Ramos de Atividade e Áreas Contaminadas

\begin{tabular}{|c|c|c|c|c|c|c|c|c|c|c|}
\hline \multirow[t]{2}{*}{ Municípios da RMC } & \multirow[b]{2}{*}{$\begin{array}{l}\text { Pop/ } \\
2014\end{array}$} & \multicolumn{6}{|c|}{ Ramos de Atividade } & \multirow{2}{*}{$\begin{array}{l}\text { Total } \\
\text { Áreas } \\
\text { Cont. }\end{array}$} & \multirow{2}{*}{$\begin{array}{c}{ }^{* A . C /} \\
10.000 \\
\text { hab. }\end{array}$} & \multirow{2}{*}{$\begin{array}{c}{ }^{* *} \text { A.M } \\
\text { /A.C } \\
\left(\mathrm{Km}^{2}\right)\end{array}$} \\
\hline & & $\begin{array}{l}\text { Área } \\
\text { Mun. } \\
\left(\mathrm{Km}^{2}\right)\end{array}$ & Posto & Ind. & $\begin{array}{l}\text { Com./ } \\
\text { Serv. }\end{array}$ & Resíd. & Agric. & & & \\
\hline Americana & 226.970 & 133,93 & 18 & 04 & 01 & 01 & - & 23 & 1,01 & 5,79 \\
\hline Artur Nogueira & 49346 & 178,03 & 06 & - & - & - & - & 06 & 1,21 & 29,62 \\
\hline Campinas & $1.154,61$ & 794,43 & 93 & 28 & 06 & 06 & - & 133 & 1,15 & 5,98 \\
\hline Cosmópolis & 65.628 & 154,66 & 04 & 04 & - & 01 & - & 09 & 1,37 & 17,19 \\
\hline Engenheiro Coelho & 18.153 & 109,94 & 01 & - & - & - & - & 01 & 0,55 & 109,79 \\
\hline Holambra & 13.046 & 65,58 & 03 & - & - & - & - & 03 & 2,29 & 21,42 \\
\hline Hortolândia & 212.527 & 62,28 & 10 & 02 & - & 01 & - & 13 & 0,61 & 4,78 \\
\hline Indaiatuba & 226.602 & 312,05 & 04 & 09 & - & 01 & 01 & 15 & 0,66 & 20,70 \\
\hline Itatiba & 111.620 & 322,23 & 07 & 14 & 01 & - & - & 21 & 1,88 & 24,64 \\
\hline Jaguariúna & 50.719 & 141,40 & 02 & 07 & - & - & - & 09 & 1,77 & 15,82 \\
\hline Monte Mor & 54462 & 240,41 & 01 & 01 & - & - & - & 02 & 0,36 & 120,39 \\
\hline Morungaba & 12.779 & 146,75 & - & - & - & - & - & - & 0,00 & 000,00 \\
\hline Nova Odessa & 56.008 & 74,32 & 01 & 02 & - & - & - & 03 & 0,53 & 24,43 \\
\hline Paulínia & 95.221 & 138,72 & 19 & 10 & 31 & 03 & 01 & 65 & 6,82 & 2,14 \\
\hline Pedreira & 45.052 & 108,59 & 01 & 08 & 01 & 01 & - & 11 & 2,44 & 9,97 \\
\hline Santa Barbara d'Oeste & 189.223 & 270,90 & 01 & 13 & - & - & - & 14 & 0,73 & 19,39 \\
\hline Santo Antônio de Posse & 22.176 & 154,00 & 01 & 01 & - & 01 & - & 03 & 1,35 & 51,37 \\
\hline Sumaré & 262.308 & 153,50 & 06 & 16 & 02 & - & - & 24 & 0,91 & 6,37 \\
\hline Valinhos & 118.302 & 148,59 & 07 & 06 & - & 03 & - & 16 & 1,35 & 9,28 \\
\hline Vinhedo & 71.217 & 81,60 & 03 & 06 & - & - & - & 09 & 1,26 & 9,08 \\
\hline Total & $3.055,97$ & $3.791,9$ & 188 & 131 & 42 & 18 & 02 & 384 & - & - \\
\hline
\end{tabular}

Fonte: elaboração do autor sobre dados da CETESB, 2013.

A Tabela 3 apresenta a relação de municípios da RMC e os tipos de atividades econômicas, que possuem maior quantidade de locais contaminados. Em primeiro lugar destacam-se os Postos de Combustíveis, com 188 áreas; em segundo lugar Indústrias, com 131 áreas; em terceiro lugar, $\mathrm{Na}$ Comércio/Serviços com, 42 áreas; em quarto lugar, Resíduos, com 18 áreas e quinto lugar, Agricultura/Acidente/Desconhecida, com duas áreas ao todo. Os municípios, que apresentam o maior acréscimo de áreas contaminadas, são Campinas e Paulínia. Campinas, que tinha 23 áreas em 2002, teve um acréscimo de 17 áreas, atingindo 40 áreas em 2007. Em Paulínia, por outro lado, foram encontradas 12 áreas em 2004, mais 09 áreas em 2009 e mais 13 em 2011. Outros casos que se destacam são Sumaré, Americana e Santa Bárbara do Oeste, 
diversos níveis, especialmente as camadas sociais mais fragilizadas. Em muitas situações, o conhecimento sobre esta realidade não tem se refletido em ações equivalentes pelos gestores públicos. Pelo contrário, o espaço territorial tem sido formulado segundo diretrizes públicas, que estimulam as atividades industriais degradantes, sem o amparo técnico municipal que averigue se estas atividades são adequadas e qual a quantidade limite que o espaço municipal pode suportar. As municipalidades têm dificuldades para organizar possíveis ações concretas, o que seria possível com os Planos de Contingencia que poderiam identificar os riscos, perigos e acidentes, vinculando-os a outras ações e meios de informação que afastem o receio e o pânico das populações residentes locais mais sensíveis. As situações vistas neste estudo, e o método de analise territorial proposto, é plausível e pode aplicado por qualquer municipalidade. Pode ser uma ferramenta complementar para leitura e compreensão, tanto da questão das contaminações, como também para complementar ações especificas e integradas para gestão destas áreas no espaço urbano e rural.

\section{AGRADECIMENTOS}

Os autores Ricardo Alexandre da Silva e Laura machado de Mello Bueno, agradecem a ANAP.

\section{REFERÊNCIAS}

ACSELRAD, Henry. Conflito Social e meio ambiente no Estado do Rio de Janeiro. Rio de Janeiro: Relume Dumará, 2004. 262p.

ACSELRAD, Henry. Tecnologias Sociais e Sistemas Locais de Poluição. Revista Horizontes Antropológicos, ano 12, n. 25. Porto Alegre: jan./jun. 2006. 21p. Disponível em: <http://www.scielo.br/pdf/ha/v12n25/a07v1225.pdf.> Acesso em 26 de junho de 2016.

BRAGA, Sandra Rodrigues. Água, uma questão para a geopolítica: reflexões sobre a hidrogeopolítica na Panamérica. Revista Estudos Amazônicos: Fronteiras e Territórios, v. 01. Tocantins: UFT, 2009. 24p. Disponível em <http://revista.uft.edu.br/index.php/amazonidas/article/view/14.> Acesso em 20 de julho de 2016.

BAENINGER, Rosana Aparecida. Região Metropolitana de Campinas - Expansão e Consolidação do Urbano Paulista. Campinas: NEPO/Unicamp, 2001. 28p. Disponível em: < https://www.researchgate.net/publication/267198747_Regiao_Metropolitana_de_Campinas_expansao_e_consolid acao_do_urbano_paulista.> Acesso em 05 de julho de 2016.

BRANCO, Samuel Murgel. O fenômeno Cubatão. São Paulo: Ver Curiosidades, 1984. 103p.

CARRARA, Amanda Camargo Heirinch: Elaboração de cenários para avaliação dos efeitos do crescimento urbano disperso sobre as emissões de GEEs: o caso de São Carlos (SP). São Carlos: EEA/USPCAR, 2014. 172 pág. Disponível em: <http://www.teses.usp.br/teses/disponiveis/18/18139/tde-25082014-084515/pt-br.php> Acesso em 05 de julho de 2016.

CARVALHO, Celso Santos; ROSSBACH, Ana Claudia. O Estatuto da Cidade Comentado: Aliança de Cidades (Cities Without Slums). Brasília: Secretaria Nacional de Programas Urbanos - Mistério das Cidades, 2013. Disponível em: <http://www.capacidades.gov.br/media/doc/acervo/8c6566990fb77e9a2177cb98fdfb1989.pdf>. Acesso em: 21 out. 2013. 
CUNHA, José Marcos Pinto da (org). Novas Metrópoles Paulistas. População, vulnerabilidade e segregação. Campinas: NEPO/Unicamp, 2006.

BUENO, Laura Machado de Mello: O saneamento na urbanização de São Paulo. São Paulo: FAU/USP, 1994.

BUENO, Laura Machado de Melo. Sociedade Sustentável em Ambientes Saudáveis: utopia em metrópoles? IN SOUZA, Maria Adélia A. de. (Org.) A metrópole e o futuro: refletindo sobre Campinas. Campinas: Territorial, 2008. $550 \mathrm{p}$.

FARIA, Bruna Fernanda: A Influência das áreas de disposição de resíduos sólidos da cidade de Campinas, SP na qualidade das águas: Determinação de metais empregando a fluorescência de raio $x$ por reflexão total com radiação Síncrotron. Faculdade de Engenharia Civil - Unicamp. Campinas, 2012. 221p. Disponível em: <http://www.bibliotecadigital.unicamp.br/document/?code=000881732f >. Acesso em: 11 de agosto de 2016.

FASE-ETTERN. Projeto avaliação de Equidade Ambienta como instrumento de democratização dos procedimentos de avaliação de impacto de projetos de desenvolvimento. Rio de Janeiro: IPPUR/UFRJ- 2011. 176p.

GUIBERLET, Jutta Cubatão. Desenvolvimento, exclusão social e degradação ambiental. São Paulo: EDUSP/FAPESP, 1996. 244p.

LOCATELLI, Marco Antônio Fernandes. Investigação sobre a emissão e caracterização dos hidrocarbonetos policíclicos aromáticos (HPA) na bacia do rio Atibaia. IQ/Unicamp. Campinas, 2006. 86p. Disponível em: <http://biq.iqm.unicamp.br/arquivos/teses/vtls000386727.pdf>. Acesso em: 01 de setembro de 2016.

MARQUES, Eduardo \& TORRES, Haroldo. São Paulo: Segregação Pobreza e Desigualdades Sociais. São Paulo: Senac, 2003. 39p.

MENDES, Andréa Danielle Janhsen. A Defesa Civil no Brasil e a Análise do Risco: Estudo de Caso na Cidade de Caratinga - Minas Gerais. Belo Horizonte: PUCMinas/PosGeo, 2011. 82p. Disponível em: <http://www.defesacivil.mg.gov.br/images/documentos/Defesa\%20Civil/pesquisa/monografia_geoprocessamento \%20_Andrea\%20Janhsen.pdf $>$. Acesso em: 01 de julho de 2016.

MINDRIZ, Ana Copat. Avaliação da contaminação da água subterrânea de poços tubulares, por combustíveis fósseis, no município de Santo André, São Paulo - Uma contribuição à Gestão Ambiental. São Paulo: IPEN/USP, 2006. 254 págs. Disponível em: <http://www.teses.usp.br/teses/disponiveis/85/85134/tde-28092006-091158/ptbr.php>. Acesso em: 01 de julho de 2016.

MOTA, Suetônio. Urbanização e meio ambiente. Rio de Janeiro: ABES, 1999. 352p.

RAMIRES, Jane Zilda dos Santos. Áreas Contaminadas e os Riscos Socioambientais em São Paulo. São Paulo: FFLGH/DGGH-USP, 2008. 174p

REZENDE, Júnia Maria Passos. O Caso Shell/Cyanamid/Basf: epidemiologia e informação para o resgate de uma precaução negada. Campinas: FCM/Unicamp, 2005. 177p. Disponível em: < http://www.bibliotecadigital.unicamp.br/document/?code=vtls000366157> Acesso em 10 de abril de 2016.

RODRIGUES, Arlete Moyses. Produção e consumo do e no espaço: problemática ambiental urbana. São Paulo: Hucitec, 1998. 193p. Disponível em <http://bibliotecadigital.puc-campinas.edu.br/services/ebooks/Arlete\%20Moyses\%20Rodrigues-1.pdf.> Acesso em 15 de maio de 2016.

SINGER, Paul. Economia Política da Urbanização. São Paulo: Brasiliense - CEBRAP, 1973. 152p.

SILVA, Ricardo Alexandre da. O Processo de Expansão Urbana Recente da Região Sudoeste de Campinas - Agentes e Impactos. Campinas: PUC-Campinas, 2013. 132p. Disponível em: <http://tede.bibliotecadigital.puc- 
